\title{
Exploring Factors Associated with Depression and Anxiety among Hospitalized Patients with Type 2 Diabetes Mellitus
}

\author{
Abdulkareem AlBekairy ${ }^{a, b}$ Salah AbuRuz ${ }^{d, e} \quad$ Bandar Alsabani $^{a}$ \\ Abdulmajeed Alshehri ${ }^{a}$ Tariq Aldebasic ${ }^{c}$ Abdulmalik Alkatheri ${ }^{a}$ b \\ Hind Almodaimegh ${ }^{a, b}$ \\ ${ }^{a}$ College of Pharmacy, King Saud bin Abdulaziz University for Health Sciences, and b Pharmaceutical Care Services \\ and ${ }^{\mathrm{C} D i v i s i o n}$ of Ophthalmology, King Abdulaziz Medical City, Riyadh, Saudi Arabia; ${ }^{\mathrm{d} C o l l e g e}$ of Pharmacy, Al Ain

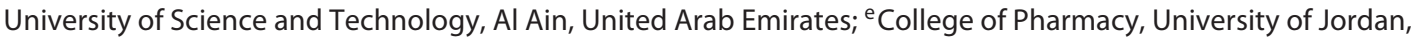 \\ Amman, Jordan
}

\section{Significance of the Study}

- In this study, the factors that increased the risk of anxiety were physical inactivity and hospitalization for 8 days or longer, and those of depression were older age, low income, and nephropathy. Anxiety and depression in hospitalized diabetic patients could increase the risk of morbidity and mortality. Hence, screening for anxiety and depression is recommended in hospitalized patients with diabetes.

\section{Keywords}

Depression · Anxiety · Internal medicine · Diabetes

\begin{abstract}
Objectives: The aims of the current study were to determine the prevalence and severity of anxiety and depression, and to explore associated factors among hospitalized patients with type 2 diabetes mellitus. Subjects and Methods: All patients with type 2 diabetes (160 patients) who were admitted to the Internal Medicine Wards of the King Abdulaziz Medical City, Riyadh, Saudi Arabia, from January to August 2015 were asked to participate, and 158 patients agreed to do so. A selfadministered questionnaire consisting of 2 parts was used. The first part was on sociodemographic information, and the second part was a validated screening tool for assessing depression and anxiety. The severity of anxiety and depression was classified as normal, mild, moderate, and severe. Logistic
\end{abstract}

\begin{tabular}{ll}
\hline KARGER & $\begin{array}{l}\text { ( } 2017 \text { The Author(s) } \\
\text { Published by S. Karger AG, Basel }\end{array}$ \\
$\begin{array}{l}\text { E-Mail karger@karger.com } \\
\text { www.karger.com/mpp }\end{array}$ & $\begin{array}{l}\text { This is an Open Access article licensed under the Creative Commons } \\
\text { Attribution-NonCommercial-4.0 International License (CC BY-NC) } \\
\text { (http://www.karger.com/Services/OpenAccessLicense), applicable to } \\
\text { the online version of the article only. Usage and distribution for com- } \\
\text { mercial purposes requires written permission. }\end{array}$
\end{tabular}

regression was carried out to identify variables that were independently associated with anxiety and depression. $\boldsymbol{R e}$ sults: Using the screening tool, 85 (53.8\%) and 80 (50.6\%) study patients were identified as patients who suffered from depression and anxiety, respectively. The severity of distress was moderate/severe in 36 (42.4\%) patients with depression and $41(51.3 \%)$ patients with anxiety. The factors independently associated with the risk for anxiety in hospitalized patients with diabetes were physical inactivity and staying 8 days or longer in the hospital. On the other hand, factors that were independently associated with the risk for depression were older age, low income, and nephropathy. Conclusion: The majority of hospitalized patients with diabetes developed moderate/severe anxiety or depression, or both, during hospitalization. Hence, screening for anxiety and depression in high-risk hospitalized diabetic patients is recommended during hospitalization.

(c) 2017 The Author(s) Published by S. Karger AG, Basel mercial purposes requires written permission. 


\section{Introduction}

Diabetes mellitus is one of the most common chronic disorders that affects millions of people worldwide [1] with a prevalence that is increasing rapidly globally and at an alarming rate especially in the Middle East and North Africa region region [2,3]. According to the International Diabetes Federation, more than 415 million people have diabetes in the world, and more than 35.4 million of these people are in the Middle East and North Africa region; it is predicted that the number will rise to $72.1 \mathrm{mil}$ lion people with diabetes by 2040 [2].

Complications and comorbidities are of particular concern in diabetes. Diabetes is usually accompanied by many comorbidities such as hypertension, dyslipidemia, and cardiovascular diseases [3]. Uncontrolled diabetes mellitus also leads to the development of many microvascular complications such as nephropathy, retinopathy, and neuropathy as well as macrovascular complications [4]. These complications and comorbidities, together with the emotional stress associated with the diagnosis of diabetes, had been linked to the development of depression and anxiety among diabetic patients $[5,6]$. It was estimated that diabetic patients have at least twice the risk of depression or anxiety compared to the general population $[7,8]$. Equally important, anxiety and depression in diabetic patients had been associated with increased risk of comorbidities, interference with daily activities and quality of life, higher health care costs, and more complications when compared to normal patients $[7,9,10]$.

A recent meta-analysis of 16 studies had revealed an alarming significant association between depression and increased risk of mortality (odds ratio, $\mathrm{OR}=1.5$ ) in patients with diabetes [11]. A study had shown that it is common for both anxiety and depression to be present together in diabetic patients, forming what can be described as anxious depression, which was identified as a strong predictor of cardiovascular outcomes [12]. Conversely, identifying and treating anxiety and depression can contribute to improved clinical outcomes $[13,14]$. Therefore, it would be imperative to investigate factors that contribute to anxiety and depression in patients with diabetes, identify patients at risk, and intervene to reduce the risk of developing anxiety or depression or both if possible. Thus far, many studies had explored factors associated with anxiety and depression among diabetic patients in outpatient settings and were able to identify several demographic, behavioral, and clinical factors that could predispose diabetic patients to depression and anxiety $[7,15,16]$. However, there is limited information about the prevalence and risk factors for anxiety and depression among hospitalized patients with diabetes. Hence, the aims of the current study were to determine the prevalence and severity of anxiety and depression, and also to explore associated factors among hospitalized patients with type 2 diabetes mellitus.

\section{Materials and Methods}

\section{Design and Setting}

A cross-sectional study was conducted at the Internal Medicine Wards, King Abdulaziz Medical City (KAMC), Riyadh, Saudi Arabia, from January to August 2015. The KAMC is a 1,200-bed tertiary-care hospital in Riyadh. The study was approved by the Institutional Review Board of the King Abdullah International Medical Research Center. A written informed consent was obtained from participants who agreed to participate in the study.

\section{Study Participants}

One hundred and sixty (160) adult patients ( $>18$ years) with type 2 diabetes who were admitted to the internal medicine wards during the study period were eligible for inclusion in this study. Diagnosis of type 2 diabetes was obtained from the patient's medical records. The inclusion criterion was a hospital stay of at least 2 days. Exclusion criteria were a previous clinical diagnosis of anxiety, depression, and other psychiatric disorder. Hence, 2 patients were excluded due to documented major depressive disorder, and 158 patients were included in the study; 122 were above 60 years of age and had uncontrolled diabetes mellitus.

\section{Data Collection}

In this study, a self-administered questionnaire consisting of 2 parts was used. The first part included patients' sociodemographic information (educational level, marital status, income, living status, job status, physical activity during hospitalization, smoking, age, and gender). The second part was a screening tool for anxiety and depression. The Arabic version of the Hospital Anxiety and Depression Scale (HADS) $[17,18]$ had been validated for use in various clinical settings including diabetes [7] and hence was used in this study. The tool was self-administered; however, in case of illiteracy or poor vision, the items and possible responses were read to the participant [19]. HADS consists of 14 items that ask the patients to reflect on their mood in the past week: 7 items assess anxiety and 7 items assess depression. Scores for items in each HADS subscale were summed to produce an anxiety score (HADSA) or a depression score (HADS-D). Each item was scored from 0 (not present) to 3 (present) [7]. Each subscale was scored as normal: 0-7; mild distress (caseness): 8-10; moderate distress: 11-14; and severe distress: $15-21$.

Clinical information (medical history, diagnosis of diabetes, medication history, laboratory data, blood pressure, and fasting plasma glucose), comorbidities, and complications (including nephropathy, retinopathy, neuropathy, stroke, hypertension, heart failure, dyslipidemia, peripheral vascular disease, and ischemic heart disease) were obtained from the patients' medical records. Based on the American Diabetes Association guidelines (2017), glycemic control was defined as $\mathrm{HbA}_{1 \mathrm{c}}$ (glycosylated hemoglobin) $<7 \%$ and fasting plasma glucose $\leq 7.2 \mathrm{mmol} / \mathrm{L}$ (average during the hospital stay). Blood pressure control was determined in accor- 
dance with the 8th Joint National Committee (JNC 8, 2013) guideline recommendations, where the recommended blood pressure goal is $<140 / 90 \mathrm{~mm} \mathrm{Hg}$ in most patients with diabetes [20]. Patients were considered physically active if they were active (e.g., walking) for at least 30 min per day during hospitalization.

\section{Analysis of Outcome Measures and Data}

Data entry and analyses were carried out using the Statistical Package for the Social Sciences (SPSS ${ }^{\circledR}$ ) (version 21.0; IBM, Armonk, NY, USA). Main study outcomes were the prevalence of anxiety and depression in hospitalized patients with diabetes and factors associated with anxiety and depression. Anxiety and depression scores were expressed as means $\pm \mathrm{SD}$. Univariate analysis was used to investigate the association between outcome variables (anxiety, depression) and sociodemographic and clinical variables using the $\chi^{2}$ test, Student $t$ test, and analysis of variance (ANOVA), as appropriate; $p<0.05$ was considered statistically significant. Variables that were identified as significant using univariate analysis were further investigated using multivariate analysis. Multivariate analysis using multiple logistic regression (backward elimination: Wald) was carried out to identify variables that were independently associated with anxiety and depression among persons with type 2 diabetes. Results of logistic regression are expressed as OR with $95 \%$ confidence interval (CI).

\section{Results}

Demographic and clinical characteristics of the study sample are shown in Table 1. The mean age of the participants was $67.2 \pm 12.6$ years.

\section{Prevalence of Anxiety and Depression}

Of the 158 patients, 85 (53.8\%) were suffering from depression, while $80(50.6 \%)$ were suffering from anxiety (Table 2). The severity of distress was moderate/severe in $36(42.4 \%)$ patients with depression and 41 (51.3\%) patients with anxiety. Additionally, 52 (32.9\%) patients had both anxiety and depression.

\section{Factors Associated with Anxiety}

Demographic factors associated with anxiety and depression are presented in Table 3. Clinical factors associated with anxiety and depression are presented in Table 4.

Factors that were associated with anxiety in hospitalized diabetic patients were: physical inactivity $(79$ [58.5\%] inactive vs. 56 active patients [41.5\%], $p=0.03$ ), longer hospital stay ( 5.18 vs. 8.15 days, $p=0.002$ ), and the number of complications (20 [58.8\%] patients with $\geq 2$ vs. 14 patients with $\leq 2$ complications [41.2\%], $p=0.03$ ) (Tables 3,4 ).

Further analysis using logistic regression (Table 5) showed that physical inactivity and longer hospital stay were independently associated with anxiety $(p<0.05)$. The risk of anxiety in physically inactive patients was 2.8

Depression and Anxiety among Type 2

Diabetes Patients
Table 1. Demographic and clinical characteristics of the study patients $(n=158)$

\begin{tabular}{|c|c|}
\hline \multicolumn{2}{|l|}{ Characteristics } \\
\hline Age (mean $\pm S D)$, years & $67.2 \pm 12.6$ \\
\hline \multicolumn{2}{|l|}{ Gender, $n(\%)$} \\
\hline Male & $84(53.2)$ \\
\hline Female & $74(46.8)$ \\
\hline \multicolumn{2}{|l|}{ Marital status, $n(\%)$} \\
\hline Single & $3(1.9)$ \\
\hline Married & $105(66.4)$ \\
\hline Widowed & $38(24.1)$ \\
\hline Divorced & $12(7.6)$ \\
\hline \multicolumn{2}{|l|}{ Income, $n(\%)$} \\
\hline$>10,000 \mathrm{SR}$ & $38(24.0)$ \\
\hline $5,000-10,000 \mathrm{SR}$ & $27(17.1)$ \\
\hline$<5,000 \mathrm{SR}$ & $93(58.9)$ \\
\hline \multicolumn{2}{|l|}{ Education, $n(\%)$} \\
\hline University degree & $18(11.4)$ \\
\hline Secondary and high school & $33(20.9)$ \\
\hline Primary school & $36(22.8)$ \\
\hline Illiterate & $71(44.9)$ \\
\hline \multicolumn{2}{|l|}{ Job status, $n(\%)$} \\
\hline Retired & $78(49.4)$ \\
\hline Unemployed & $63(39.9)$ \\
\hline Employed & $17(10.8)$ \\
\hline \multicolumn{2}{|l|}{ Living status, $n(\%)$} \\
\hline With full family & $97(61.4)$ \\
\hline With sons & $49(31.0)$ \\
\hline With spouse & $10(6.3)$ \\
\hline Living alone & $2(1.3)$ \\
\hline \multicolumn{2}{|l|}{ Physical activity, $n(\%)$} \\
\hline Active & $23(14.6)$ \\
\hline Inactive & $135(85.4)$ \\
\hline \multicolumn{2}{|l|}{ Smoking, $n(\%)$} \\
\hline Non-/ex-smoker & $147(93)$ \\
\hline Current smoker & $11(7)$ \\
\hline $\mathrm{BMI}($ mean $\pm \mathrm{SD})$ & $30.52 \pm 7.61$ \\
\hline Fasting blood glucose (mean $\pm \mathrm{SD}$ ), $\mathrm{mmol} / \mathrm{L}$ & $10.14 \pm 3.97$ \\
\hline Duration of diabetes (mean $\pm S D$ ), years & $15.48 \pm 9.74$ \\
\hline $\mathrm{HbA}_{1 \mathrm{c}}($ mean $\pm \mathrm{SD}), \%$ & $8.56 \pm 1.94$ \\
\hline \multicolumn{2}{|l|}{ Control of diabetes, $n(\%)$} \\
\hline Controlled & $34(21.5)$ \\
\hline Uncontrolled & $122(77.2)$ \\
\hline \multicolumn{2}{|l|}{ Types of medications, $n(\%)$} \\
\hline Lifestyle only & $22(13.9)$ \\
\hline Insulin use & $100(63.3)$ \\
\hline Oral agents only & $36(22.8)$ \\
\hline Length of hospital stay (mean \pm SD), days & $6.68 \pm 6.01$ \\
\hline \multicolumn{2}{|c|}{ Presence of micro- and macrovascular complications, $n(\%)$} \\
\hline Yes & $118(74.6)$ \\
\hline No & $40(25.3)$ \\
\hline Number of comorbidities (mean \pm SD) & $2.9 \pm 1.1$ \\
\hline \multicolumn{2}{|l|}{ Comorbidities and complications, $n(\%)$} \\
\hline Hypertension & $116(73.4)$ \\
\hline Ischemic heart disease & $66(41.8)$ \\
\hline Dyslipidemia & $64(40.5)$ \\
\hline Heart failure & $48(30.4)$ \\
\hline Stroke & $17(10.8)$ \\
\hline Nephropathy & $34(21.5)$ \\
\hline Neuropathy & $5(3.1)$ \\
\hline Retinopathy & $5(3.1)$ \\
\hline
\end{tabular}


Table 2. Prevalence of anxiety and depression among hospitalized diabetic patients $(n=158)$

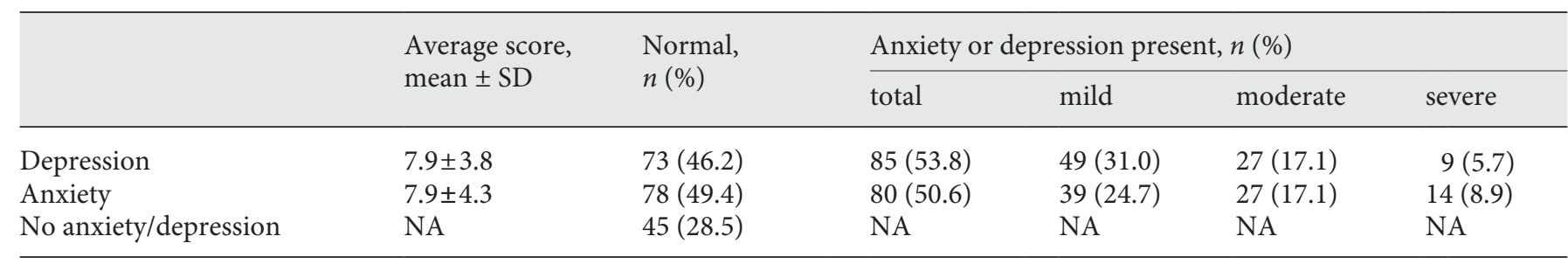

Table 3. Demographic factors associated with anxiety and depression (univariate analysis)

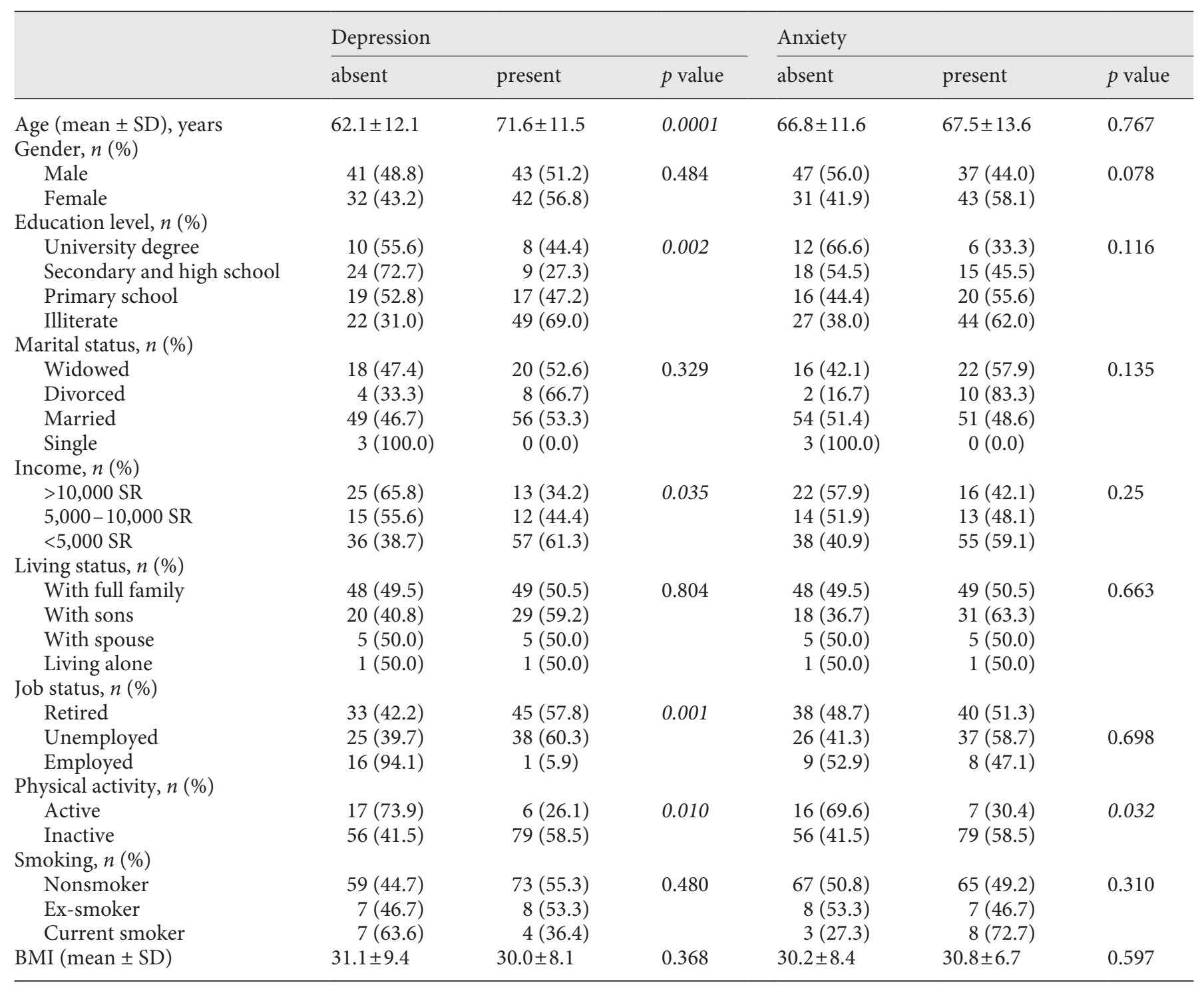

Statistically significant $p$ values are italicized. 
Table 4. Clinical factors associated with anxiety and depression (univariate analysis)

\begin{tabular}{|c|c|c|c|c|c|c|}
\hline & absent & present & $p$ value & absent & present & $p$ value \\
\hline Hospitalization (mean $\pm \mathrm{SD}$ ), days & $6.38 \pm 6.2$ & $6.94 \pm 5.8$ & 0.563 & $5.18 \pm 5.1$ & $8.15 \pm 6.5$ & 0.002 \\
\hline \multicolumn{7}{|l|}{ Types of medications, $n(\%)$} \\
\hline Lifestyle only & $13(59.1)$ & $9(40.9)$ & 0.401 & $15(68.2)$ & $7(31.8)$ & 0.143 \\
\hline $\mathrm{HbA}_{1 \mathrm{c}}($ mean $\pm \mathrm{SD}), \%$ & $8.69 \pm 1.96$ & $8.45 \pm 1.92$ & 0.455 & $8.52 \pm 1.81$ & $8.59 \pm 2.06$ & 0.821 \\
\hline $\mathrm{FPG}($ mean $\pm \mathrm{SD}), \mathrm{mmol} / \mathrm{L}$ & $9.88 \pm 3.91$ & $10.34 \pm 4.03$ & 0.479 & $10.44 \pm 4.21$ & $9.84 \pm 3.74$ & 0.349 \\
\hline \multicolumn{7}{|l|}{ Diabetes mellitus, $n(\%)$} \\
\hline Controlled & $18(21.2)$ & $16(21.9)$ & \multirow[t]{2}{*}{0.987} & $17(21.2)$ & $17(21.8)$ & \multirow[t]{2}{*}{0.996} \\
\hline Uncontrolled & $66(77.6)$ & $56(76.7)$ & & $62(77.5)$ & $60(76.9)$ & \\
\hline 0 & $17(42.5)$ & $23(57.5)$ & \multirow[t]{3}{*}{0.03} & $15(37.5)$ & $25(62.5)$ & \multirow[t]{3}{*}{0.03} \\
\hline 1 & $47(56.0)$ & $37(44.0)$ & & $50(59.5)$ & $34(40.5)$ & \\
\hline$\geq 2$ & $10(29.4)$ & $24(70.6)$ & & $14(41.2)$ & $20(58.8)$ & \\
\hline \multicolumn{7}{|l|}{ Hypertension, $n(\%)$} \\
\hline Yes & $48(41.4)$ & $68(58.6)$ & \multirow[t]{2}{*}{0.03} & $58(50.0)$ & $58(50.0)$ & \multirow[t]{2}{*}{1} \\
\hline No & $26(61.9)$ & $16(38.1)$ & & $21(50.0)$ & $21(50.0)$ & \\
\hline \multicolumn{7}{|l|}{ Dyslipidemia, $n(\%)$} \\
\hline Yes & $31(48.4)$ & $33(51.6)$ & \multirow[t]{2}{*}{0.75} & $35(54.7)$ & $29(45.3)$ & \multirow[t]{2}{*}{0.42} \\
\hline No & $43(45.7)$ & $51(54.3)$ & & $44(46.8)$ & $50(53.2)$ & \\
\hline \multicolumn{7}{|l|}{ Heart failure, $n(\%)$} \\
\hline Yes & $23(47.9)$ & $25(52.1)$ & \multirow[t]{2}{*}{0.86} & $20(60.4)$ & $19(39.6)$ & \multirow[t]{2}{*}{0.12} \\
\hline No & $51(64.4)$ & $59(53.6)$ & & $50(45.5)$ & $60(54.5)$ & \\
\hline
\end{tabular}

Statistically significant $p$ values are italicized. FPG, fasting plasma glucose.

times higher than in those who were physically active ( $p=0.026, \mathrm{CI}=1.13-6.78)$. Length of hospital stay was also associated with an OR of $1.1(p=0.002, \mathrm{CI}=1.04-$ 1.19). Further data analysis on this association using ANOVA identified that the severity of anxiety was increasing with longer hospital stay, where the length of stay increased from an average of 5.2 days for patients without anxiety to $7,8.4$, and 10.9 days for patients with mild, moderate, and severe anxiety, respectively $(p=$ $0.001)$. Statistical analysis indicated no association between anxiety and indicators of disease severity such as $\mathrm{HbA}_{1 \mathrm{c}}$, fasting plasma glucose, and diabetes duration.

\section{Factors Associated with Depression}

Factors that were associated with depression in hospitalized diabetic patients were older age $(p=0.0001)$, low- er educational level ( $p=0.006)$, lower income (less than SR [Saudi Riyals] 5,000/USD 1,333 per month) $(p=$ $0.035)$, job status (retired or unemployed) $(p=0.001)$, higher number of complications $(p=0.03)$, hypertension $(p=0.03)$, nephropathy $(p=0.03)$, and physical inactivity $(p=0.01)$ (Tables 3,4$)$.

Further analysis using logistic regression (Table 5) revealed that older age, lower income, and nephropathy were independently associated with depression $(p<0.05)$. The risk of depression in lower-income patients was 1.96 times increased compared to higher income patients $(p=$ $0.006, \mathrm{CI}=1.21-3.18$ ). Patients with nephropathy also had 4.3 times the risk of depression as compared to those without depression $(p=0.01, \mathrm{CI}=1.36-13.53)$. Age was also associated with an OR of $1.08(p=0.0001, \mathrm{CI}=1.04-$ 1.12). Statistical analysis indicated no association be- 
Table 5. Logistic regression for variables associated with anxiety and depression

\begin{tabular}{llll}
\hline Variable & OR & $95 \% \mathrm{CI}$ & $p$ value \\
\hline Depression & & & \\
Age & 1.08 & $1.04-1.12$ & 0.000 \\
Low income & 1.96 & $1.21-3.18$ & 0.006 \\
Nephropathy & 4.28 & $1.36-13.53$ & 0.013 \\
\hline Anxiety & & & \\
Long hospital stay & 1.11 & $1.04-1.19$ & 0.002 \\
Physical inactivity & 2.77 & $1.13-6.78$ & 0.026 \\
\hline
\end{tabular}

tween depression and indicators of disease severity such as $\mathrm{HbA}_{1 \mathrm{c}}$, fasting plasma glucose, and diabetes duration.

\section{Discussion}

In this study, the prevalence of anxiety and depression was very high. More than $50 \%$ of hospitalized patients with diabetes showed symptoms of either anxiety or depression, while $32.9 \%$ had both anxiety and depression. The severity of distress was moderate/severe in $51.3 \%$ of the patients with anxiety and $42.4 \%$ in patients with depression. Logistic regression analysis revealed that hospitalized patients with diabetes were more prone to anxiety if they were physically inactive or if they stayed 8 days or longer in hospital. On the other hand, factors that independently increased the risk for depression as identified by logistic regression were older age, lower income, and having nephropathy.

The results of the current study showed a much higher prevalence of anxiety and depression in hospitalized patients than in outpatients with diabetes [21-28]. The higher prevalence identified in the current study could be attributed to the social isolation, reduced mobility, acute illness, and many other factors that are associated with hospital stay. In this study, depression was more common in older patients probably due to higher disease severity, reduced mobility, multiple chronic conditions, and reduced social interactions in older patients. Encouraging social interactions and physical activities could help reduce the occurrence of depression during hospitalization. The effectiveness of such interventions should be investigated.

This study showed that physical inactivity was the only modifiable risk factor which contributed to both depression and anxiety during hospitalization. Physical inactivity and sedentary lifestyle are major problems in Saudi
Arabia, as shown in a recent study in which a very high prevalence of physical inactivity among Saudis was reported as the predisposing factor to many diseases [29].

The finding that anxiety was significantly associated with length of hospital stay was important because patients with anxiety had an average length of hospital stay of 8 days or longer compared with an average of 5 days for those without anxiety. The severity of anxiety was also associated with the length of hospital stay. Thus, reducing unnecessary hospital stay in diabetic patients could reduce the possibility of developing anxiety. Since these results indicate only association rather than causality, it should be expected that anxiety could also be contributing to longer hospital stay.

In this study, nephropathy had the strongest impact on depression with a 4 times increased risk. This finding could be related to the many medications, monitoring parameters, and dose adjustments that may be required during hospitalization for patients with nephropathy.

The main limitation of the study was the small sample size. The use of HADS is limited by the fact that this is a screening tool, and that anxiety and depression should be confirmed with clinical diagnosis. A future study should investigate factors affecting anxiety and depression in patients with previous psychiatric illness during hospitalization. In hospitalized patients with diabetes, physical activities and social interactions, which are recommended as strategies for preventing anxiety and depression, should also be explored.

\section{Conclusion}

The majority of patients with diabetes had developed moderate/severe anxiety or depression, or both, during hospitalization. Hospitalized patients with diabetes were at higher risk for anxiety if they were physically inactive and stayed 8 days or longer in hospital. The risk for depression was higher in patients with a low income, patients with nephropathy, and older patients. Screening for anxiety and depression in high-risk patients is recommended during hospitalization. Strategies aiming at the prevention of anxiety and depression, such as recommending an acceptable level of physical activities or engaging in social interactions during hospitalization, should be explored.

\section{Disclosure Statement}

The authors have no conflict of interest. 


\section{References}

1 Kinaan M, Ding H, Triggle CR: Metformin: an old drug for the treatment of diabetes but a new drug for the protection of the endothelium. Med Princ Pract 2015;24:401-415.

2 International Diabetes Federation. https:// www.idf.org/our-network/regions-members/middle-east-and-north-africa/members (accessed March 2017).

3 Dagogo-Jack S: Metabolomic prediction of diabetes and cardiovascular risk. Med Princ Pract 2012;21:401-403.

4 Shehab D, Al-Jarallah K, Abdella N, et al: Prospective evaluation of the effect of short-term oral vitamin D supplementation on peripheral neuropathy in type 2 diabetes mellitus. Med Princ Pract 2015;24:250-256.

5 Gonzalez JS Esbitt SA, Schneider HE, et al: Psychological issues in adults with type 2 diabetes; in Pagoto S (eds): Psychological CoMorbidities of Physical Illness: A Behavioral Medicine Perspective. New York, Springer Science Business Media LLC, 2011, pp 73 121.

6 Yekta Z, Pourali R, Yavarian R: Behavioural and clinical factors associated with depression among individuals with diabetes. East Mediterr Health J 2010;16:286-291.

7 Khuwaja AK, Lalani S, Dhanani R, et al: Anxiety and depression among outpatients with type 2 diabetes: a multi-centre study of prevalence and associated factors. Diabetol Metab Syndr 2010;2:72.

8 Nichols L, Barton PL, Glazner J, et al: Diabetes, minor depression and health care utilization and expenditures: a retrospective database study. Cost Eff Resour Alloc 2007;5:4.

9 Engum A, Mykletun A, Midthjell K, et al: Depression and diabetes: a large populationbased study of sociodemographic, lifestyle, and clinical factors associated with depression in type 1 and type 2 diabetes. Diabetes Care 2005;28:1904-1909.
10 Egede LE, Zheng D, Simpson K: Comorbid depression is associated with increased health care use and expenditures in individuals with diabetes. Diabetes Care 2002;25:464-470.

11 van Dooren FE, Nefs G, Schram MT, et al: Depression and risk of mortality in people with diabetes mellitus: a systematic review and meta-analysis. PLoS One 2013;8:e57058.

12 Bruce DG, Davis WA, Dragovic M, et al: Comorbid anxiety and depression and their impact on cardiovascular disease in type 2 diabetes: the Fremantle Diabetes Study phase II. Depress Anxiety 2016;33:960-966.

13 Simon GE, Katon WJ, Lin EH, et al: Cost-effectiveness of systematic depression treatment among people with diabetes mellitus. Arch Gen Psychiatry 2007;64:65-72.

14 Katon W: Depression and diabetes: unhealthy bedfellows. Depress Anxiety 2010;27:323326.

15 Ganasegeran K, Renganathan P, Manaf RA, et al: Factors associated with anxiety and depression among type 2 diabetes outpatients in $\mathrm{Ma}$ laysia: a descriptive cross-sectional singlecentre study. BMJ Open 2014;4:e004794.

16 Katon W, Russo J, Lin EH, et al: Depression and diabetes: factors associated with major depression at five-year follow-up. Psychosomatics 2009;50:570-579.

17 Hassan HA, Suriya MO, Al-Aseri ZA, et al: Feasibility of using Arabic Hospital Anxiety and Depression Scale (HADS) to assess anxiety and depression among patients attending accident and emergency at a university hospital setting in Riyadh, Saudi Arabia. Pak J Med Sci 2015;31:1366-1371.

18 Al Aseri ZA, Suriya MO, Hassan HA, et al: Reliability and validity of the Hospital Anxiety and Depression Scale in an emergency department in Saudi Arabia: a cross-sectional observational study. BMC Emerg Med 2015; $15: 28$.
19 Snaith RP: The Hospital Anxiety and Depression Scale. Health Qual Life Outcomes 2003. $1: 29$.

20 Armstrong C: JNC8 guidelines for the management of hypertension in adults. Am Fam Physician 2014;90:503-504.

21 Al-Amer RM, Sobeh MM, Zayed AA, et al: Depression among adults with diabetes in Jordan: risk factors and relationship to blood sugar control. J Diabetes Complications 2011; 25:247-252.

22 Anaforoglu I, Ramazanogullari I, Algun E, et al: Depression, anxiety and quality of life of family caregivers of patients with type 2 diabetes. Med Princ Pract 2012;21:360-365.

23 Arshad AR, Alvi KY: Frequency of depression in type 2 diabetes mellitus and an analysis of predictive factors. J Pak Med Assoc 2016;66: 425-429.

24 Collins MM, Corcoran P, Perry IJ: Anxiety and depression symptoms in patients with diabetes. Diabet Med 2009;26:153-161.

25 Gemeay EM, Moawed SA, Mansour EA, et al: The association between diabetes and depression. Saudi Med J 2015;36:1210-1215.

26 Masmoudi J, Damak R, Zouari H, et al: Prevalence and impact of anxiety and depression on type 2 diabetes in Tunisian patients over sixty years old. Depress Res Treat 2013;2013: 341782.

27 Rajput R, Gehlawat P, Gehlan D, et al: Prevalence and predictors of depression and anxiety in patients of diabetes mellitus in a tertiary care center. Indian J Endocrinol Metab 2016; 20:746-751.

28 Tellez-Zenteno JF, Cardiel MH: Risk factors associated with depression in patients with type 2 diabetes mellitus. Arch Med Res 2002; 33:53-60.

29 Al-Zalabani AH, Al-Hamdan NA, Saeed AA: The prevalence of physical activity and its socioeconomic correlates in Kingdom of Saudi Arabia: a cross-sectional population-based national survey. J Taibah Univ Med Sci 2015; 10:208-215. 